\title{
Aging in Europe: Reforms, international diversifica- tion and behavioral reactions
}

\author{
Axel Börsch-Supan ${ }^{\mathrm{a}}$, Klaus Härtl ${ }^{\mathrm{a}}$ and Alexander Ludwig ${ }^{\mathrm{a}, \mathrm{b}}$ \\ ${ }^{a}$ Munich Research Institute for the Economics of Aging (MEA) \\ ${ }^{\mathrm{b}} \mathrm{CMR}$, University of Cologne \\ Technical appendix
}

This annex describes our dynamic open-economy macroeconomic model that allows us to analyze the effects of the labor market reforms on GDP and consumption per capita in an aging Europe. Main feature is the specification of labor supply with an endogenous and an exogenous component. While we treat the reforms and the resulting variation in the maximum labor supply as exogenous, households in our model endogenously adjust their hours worked up to that maximum and may thus counteract parts of the labor market reforms.

\section{Demography}

Time in our model is discrete and extends from $t=0, \ldots, T$. Each model period $t$ reflects a time interval of 5 years. Our demographic projections, however, are more detailed with an annual periodicity. These detailed demographic projections form the background of our analysis. Demography is taken as exogenous. It represents one of the main driving force of our simulation model, in addition to exogenous changes in labor supply restrictions and pension policy changes.

Households in our model economies enter economic life at age 15 which we denote by $j=0$. The maximum age is 100 years. Accordingly, the maximum economic age, denoted by $J$, is 85. We assume that households give birth between ages $0, \ldots, j f$, the age of menopause. Migration is assumed to be done by the age of $15(j=0)$ so that we can treat newborns and immigrants in the economic model alike. Accordingly, in each country $i$, the size of population of age $j$ in period $t, N_{t, j, i}$, is given recursively by 
(1) $\quad N_{t+1, j+1, i}=N_{t, j, i} \varsigma_{t, j, i}$ for $j>0$ and $N_{t+1,0, i}=\sum_{j=0}^{j f} f_{t, j, i} N_{t, j, i}+M_{t, 0, i}$,

where $\varsigma_{t, j, i}$ denotes the age-specific conditional survival rate, $f_{t, j, i}$ the age-specific fertility rate and $M_{t, 0, I}$ the net migration into country $i$. We assume that the total fertility rate is constant until 2050 as in the constant fertility variant of United Nations World Population Prospects (United Nations 2012). Life expectancy is computed from life tables provided by the Human Mortality Base (2012) and projected into the future by applying the Lee-Carter method (Lee and Carter 1992). Data and assumptions on migration is again taken from United Nations (2012). Table 1 summarizes the information on total fertility rates and life expectancies at birth.

TABLE 1: Total fertility rates and life expectancies

\begin{tabular}{lll}
\hline \hline Life expectancy & 2010 & 2050 \\
\hline France & 79.95 & 86.29 \\
Germany & 78.88 & 84.72 \\
Italy & 80.81 & 87.43 \\
United States & 77.68 & 83.01 \\
\hline Total fertility rate & 2010 & 2050 \\
\hline France & 1.90 & 1.90 \\
Germany & 1.36 & 1.36 \\
Italy & 1.33 & 1.33 \\
United States & 2.01 & 2.01 \\
\hline \hline
\end{tabular}

Notes: Data for Germany are for West Germany. Source: Authors' computations based on United Nations (2012) and Human Mortality Database (2012).

\section{Production}

The production sector in each country consists of a representative firm that uses a CobbDouglas production function given by

$$
\text { (2) } \quad Y_{t, i}=F\left(\Omega_{t, i}, K_{t, i}, L_{t, i}\right)=\Omega_{t, i} K_{t, i}^{\alpha} L_{t, i}^{1-\alpha},
$$

where $K_{t, i}$ denotes the capital stock and $L_{t, i}$ is aggregate effective labor supply of country $i$ at time $t . \alpha$ is the capital share and $\Omega_{t, i}$ is the technology level of country $i$ growing at the exogenous rate $g$. 
The firm's problem is static such that wages and interest rates are given by

$$
\begin{aligned}
& \text { (3) } w_{t, i}=\Omega_{t, i}(1-\alpha) k_{t}^{\alpha} \text {, } \\
& \text { (4) } r_{t}=\alpha k_{t}^{\alpha}-\delta,
\end{aligned}
$$

where $k_{t}$ is the capital stock per efficient unit of labor and $\delta$ is the depreciation rate of capital.

\section{Households}

A household faces an exogenously given limit $l_{t, j, i}$ of joint hours of labor supply. The household endogenously decides on the fraction of hours $h_{t, j, i}$ which are actually supplied, with $0 \leq h_{t, j, i} \leq 1$. Accordingly, total labor supply of a household is given by the product of the two components, $l_{t, j, i} \cdot h_{t, j, i}$, and total leisure is $1-l_{t, j, i} \cdot h_{t, j, i}$.

The household derives utility from consumption $c_{t, j, i}$ and leisure $1-l_{t, j, i} \cdot h_{t, j, i}$ and the household's per period utility function is given by

$$
u\left(c_{t, j, i}, 1-h_{t, j, i} \cdot l_{t, j, i}\right)=\frac{1}{1-\theta}\left(c_{t, j, i}^{\phi}\left(1-l_{t, j, i} h_{t, j, i}\right)^{1-\phi}\right)^{1-\theta} .
$$

The maximization problem of a cohort born in period $t$ at $j=0$ is given by

$$
\max \sum_{j=0}^{J} \beta^{j} \pi_{t, j, i} u\left(c_{t+j, j, i} 1-l_{t+j, j, i} h_{t+j, j, i}\right)
$$

where $\beta$ is the pure time discount factor. In addition to pure discounting, households discount future utility with their unconditional survival probability, $\pi_{t, j}=\prod_{k=0}^{j} s_{t+k, k}$.

Here, $s_{t+k, k, i}$ denotes the probability to survive from period $t+k$, age $k$ to period $t+k+1$, age $k+1$ in country $i$ with $s_{t, 0, i}=1$.

A feature of our model is uncertainty about the time of death expressed in the term $\pi_{t, j, i}$ in equation (5). We assume that accidental bequests resulting from premature death are taxed by the government at a confiscatory rate and used for otherwise neutral government consumption. ${ }^{1}$ We do not include intended bequests in our model.

\footnotetext{
1 An alternative assumption would be to redistribute accidental bequests to the population according to some scheme. The redistribution would however not affect our results much and we therefore opted for this simplifying assumption.
} 
Labor productivity changes over the life-cycle according to age-specific productivity parameters $\varepsilon_{j}$. Hence, the age-specific wage is $w_{t, j, i}=w_{t, i} \cdot \varepsilon_{j}$.

Denoting total assets by $a_{t, j, i}$, maximization of the household's intertemporal utility is subject to a dynamic budget constraint given by

$$
a_{t+1, j+1, i}=a_{t, j}\left(1+r_{t}\right)+\lambda l_{t, j, i} h_{t, j, i} w_{t, j, i}\left(1-\tau_{t, i}\right)+(1-\lambda) p_{t, j, i}-c_{t, j, i}
$$

where $\lambda=1$ for $j=0, \ldots, j r$ and $\lambda=0$ for $j>j r$ and $j r$ is the exogenous retirement age. $\tau_{t, i}$ is the contribution rate to a PAYG financed public pension system and $p_{t, j, i}$ is pension income, see below.

Furthermore, maximization is subject to the constraint that the fraction of the households' maximum possible work hours which is actually supplied is positive and may not exceed one

$$
\text { (7) } \quad 0 \leq h_{t, j, i} \leq 1
$$

In the variant of our model with fully exogenous labor supply we replace the constraint (7) with the constraint that $h_{t, j, i}=1$ for all $t, j, i$.

\section{Pensions and pension reform}

The only purpose of the government in our model is to organize a prototypical public pension system that is pay-as-you-go financed. Pension payments are earnings related. Precisely, pension payments are given by

$$
p_{t, i}=\rho_{\mathrm{t}, \mathrm{i}} w_{\mathrm{t}, \mathrm{i}}\left(1-\tau_{\mathrm{t}, \mathrm{i}}\right) s_{\mathrm{t}, \mathrm{j}, \mathrm{i}}
$$

where $\rho_{t, i}$ denotes the net replacement rate (generosity of the pension system) and $\tau_{t, i}$ the contribution rate of the pension system in $t, i$. $s_{t, i, j}$ is the pension stock - capturing the earnings related component of the system - which accumulates over the life-cycle according to

$$
s_{\mathrm{t}+1, \mathrm{j}+1, \mathrm{i}}=s_{\mathrm{t}, \mathrm{j}, \mathrm{i}}+\frac{\varepsilon_{j} l_{\mathrm{t}, \mathrm{j}, \mathrm{i}} h_{\mathrm{t}, \mathrm{j}, \mathrm{i}}}{j r \cdot \bar{h}_{t, i}}, \text { where } \quad \bar{h}_{t, i}=\frac{\sum_{j=1}^{j r} \varepsilon_{j} l_{\mathrm{t}, \mathrm{j}, \mathrm{i}} h_{\mathrm{t}, \mathrm{j}, \mathrm{i}} N_{\mathrm{t}, \mathrm{j}, \mathrm{i}}}{j r \cdot \sum_{j=1}^{j r} l_{\mathrm{t}, \mathrm{j}, \mathrm{h}} h_{\mathrm{t}, \mathrm{j}, \mathrm{i}} N_{\mathrm{t}, \mathrm{j}, \mathrm{i}}} .
$$

Accordingly, households earn one earnings point if they receive average wage income in a given period and earning points are normalized by the length of the working period, $j r$. In our model without cross-sectional heterogeneity, differences in wage income are only induced by 
age productivity. The scheme approximates well the current legislation in Germany and France with their earnings point systems, and Italy with the new entrants' notional defined contribution system.

Households fully understand the linkage between contributions to the pension system and pension payments in old age. Therefore, relative to a Beveridgian pension system - in which pension payments are lump-sum - labor supply distortions are smaller in such a Bismarckian scheme because of the earnings related linkage. They are not zero, however, as often claimed in the public debate, because the rate of return on the capital market exceeds the implicit return of the pension system in a dynamically efficient economy ${ }^{2}$ to the effect that labor is distorted. Due to compounded interest, this effect is stronger for younger households and monotonically decreases (but never becomes zero) with age.

We assume that the budget of the pension system is balanced in all $t, i$ such that

$$
p_{t, i} \sum_{j=j r+1}^{J} N_{t, i, j}=w_{\mathrm{t}, \mathrm{i}} \tau_{\mathrm{t}, \mathrm{i}} \sum_{j=1}^{j r} N_{t, i, j}
$$

The main policy parameter is the net replacement rate $\rho$; the contribution rate $\tau$ responds passively to balance the pension system's budget. If $\rho$ is large, public pensions crowd out private saving through the households consumption/saving decision given by (5) and (6).

If $\rho=0$, all old age provision will be private savings. This represents the textbook life-cycle model in which intertemporal consumption smoothing over the life cycle provides the retirement income through saving in young age and dissaving after retirement.

\section{Equilibrium}

We define equilibrium in this economy sequentially. Given initial capital stocks $K_{0, i}$, a competitive equilibrium of the economy is defined as sequences of disaggregate variables for the households, $\left\{c_{t, j, i}, l_{t, j, i}, h_{t, j, i}, a_{t, j, i}\right\}$, sequences of aggregate variables, $\left\{C_{t, i}, L_{t, i}, K_{t, i}\right\}$, prices for labor as well as contribution rates to the pension system, $\left\{w_{t, i}, \tau_{t, i}\right\}$, in each country $i$, and a common world interest rate $\left\{r_{t}\right\}$ such that

\footnotetext{
${ }^{2}$ We calibrate our model such that the economy is dynamically efficient.
} 
1. Given prices and initial conditions, households maximize life-time utility in (5) subject to the constraints in (6) to (9).

2. Factor prices equal their marginal productivities as given in equations (3) and (4).

3. Government policies satisfy (8) in every period and

$$
G_{t+1, i}=\sum_{j=1}^{J} a_{t+1, j+1, i} N_{t, j, i}\left(1-\varsigma_{t, j, i}\right),
$$

where $G_{t, i}$ is (otherwise neutral) government consumption (financed by taxing accidental bequests at a confiscatory rate).

4. All markets clear in all $t, i$.

$$
\begin{aligned}
& L_{t, i}=\sum_{j=0}^{J} \varepsilon_{j} l_{t, j, i} h_{t, j, i} N_{t, j, i} \text { for all } t, i \\
& \sum_{i=1}^{I} K_{t+1, i}=\sum_{i=1}^{I} \sum_{j=0}^{J} a_{t+1, j+1, i} N_{t, j, i} \\
& \sum_{i=1}^{I} \sum_{j=0}^{J} c_{t, j, i} N_{t, j, i}+\sum_{i=1}^{I} K_{t+1, i}+\sum_{i=1}^{I} G_{t, i}=\sum_{i=1}^{I} \Omega_{t, i} K_{t, i}^{\alpha} L_{t, i}^{1-\alpha}-(1-\delta) \sum_{i=1}^{I} K_{t, i}
\end{aligned}
$$

\section{Numerical implementation}

Our time line has four periods: a phase-in period, a calibration period, a projection period, and a phase-out period. First, we start calculations 110 years before the calibration period begins with the assumption of an "artificial" initial steady state in 1850 . The time period between 1960 and 2010 is then used as calibration period in order to determine the structural parameters of the model. Our projections run from 2010 through 2100. Results are displayed until year 2050 to show the main period of population aging. The phase-out period after 2100 has two parts: a transition to a steady-state population in 2200 and an additional 100-year period until the macroeconomic model reaches a final steady state in 2300 .

For each sequence of outer loop variables (see below), we solve the household model by looping backward in age, applying first-order methods and appropriately handling the constraints. We can characterize solutions in closed form, conditional on guesses for final asset holdings 
of households (respectively final consumption), $a_{\mathrm{J}}$, for each period $t$ and country $i$. To avoid costly inner loops for solution of the household model, we update these guesses jointly with other outer loop variables as described next.

We determine the equilibrium path of the overlapping generations model by using the GaussSeidel-Quasi-Newton method developed by Ludwig (2007). The algorithm searches for equilibrium paths (outer loop variables) of capital to output ratios, pension contribution rates (or, depending on the pension system scenario, replacement rates), average earnings and final period household assets in each country.

\section{Calibration}

We solve the model at a 5 year frequency. We calibrate a subset of structural model parameters as first-stage parameters without using the model. Accordingly, we set the capital share $\alpha$ to 0.40 , based on estimates of the wage share. We set the long-run growth rate of productivity $g$ to 0.015 based on estimates of real TFP growth in OECD countries. The depreciation rate $\delta$ is $5 \%$ which, given our calibration target of a capital output ratio of 2.65 (based on estimates of the stock of fixed assets to output) and our choice of the capital share implies an investment to output ratio of about $20 \%$. The inter-temporal elasticity of substitution (IES, $1 / \theta$ ) is set to 0.5 by reference to other studies, see, e.g., the review provided in Bansal and Yaron (2004).

The discount factor as well as the consumption weight in the utility function are calibrated by using the model such that it produces a capital output ratio of about 2.65 and a share of time devoted to labor of about one third. This requires setting the discount factor $\beta$ close to one (0.99), i.e., pure time discounting is weak. Recall, however, that households discount future utility with the probability of surviving into the future. The value of the consumption share in utility $\varphi$ is 0.66 . 
TABLE 2: Structural model parameters

\begin{tabular}{ll}
\hline \hline$\alpha$ : capital share in production & 0.40 \\
$g:$ growth rate of labor productivity & 0.015 \\
$\delta$ : depreciation rate of capital & 0.05 \\
$\Omega_{i}$ : technology level & $0.05-0.07$ \\
$\beta$ : discount factor & 0.99 \\
$\theta:$ inverse inter-temporal substation elasticity & 2.0 \\
$\varphi:$ consumption share parameter & 0.66 \\
\hline \hline
\end{tabular}

\section{Bibliography}

Bansal, R. and A. Yaron (2004). Risks for the long run: A potential resolution of asset pricing puzzles. The Journal of Finance 59 (4), 1481-1509.

Human Mortality Database (2012). University of California, Berkeley (USA), and Max Planck Institute for Demographic Research (Germany). www.mortality.org.

Lee, R. D. and L. Carter (1992). Modeling and Forecasting U.S. Mortality. Journal of the American Statistical Association 87, 659-671.

Ludwig, A. (2007). The Gauss-Seidel-Quasi-Newton method: A hybrid algorithm for solving dynamic economic models. Journal of Economic Dynamics \& Control 31, 1610-1632.

United Nations (2012). World Population Prospects: The 2012 Revision. United Nations Population Division. New York. 